\title{
Alternative Method of Mitigating Risk on Medium and Large Corporations
}

\author{
Raude John O. Messo ${ }^{1}$ \\ ${ }^{1}$ Department of Business Management, School of Business and Economics, Masinde Muliro University of \\ Science and Technology, Kenya \\ Correspondence: Raude John O. Messo, Department of Business Management, School of Business and \\ Economics, Masinde Muliro University of Science and Technology, Kenya. E-mail: johnmesso@yahoo.com
}

Received: July 30, 2016

doi:10.5539/ijbm.v11n11p164
Accepted: September 9, $2016 \quad$ Online Published: October 27, 2016

URL: http://dx.doi.org/10.5539/ijbm.v11n11p164

\begin{abstract}
High operating costs and complexity of risks are impacting negatively on corporations' profitability despite practicing corporate governance. Corporate governance requires that the management develops frameworks, structures and guidance to manage enterprise risk. The traditional methods of mitigating risk has relied heavily on insurance as the only mean of protecting enterprise against risks. This is now becoming too expensive for corporations, and, is not able to cover all risk exposures. This forms the basis of the research problem in this study. The purpose and objective of this study is to establish alternative methods of mitigating risks in corporations and, develop models for computing benefits accruing to the corporations as a result of using the new alternative method. As such, this study identifies financial assets, sinking fund, ploughing back of premiums as possible investments where foregone insurance premiums can be invested and, develop a model for computing earnings resulting from such investments. This study applies Actuarial Theory, Financial Theory of Risk Transfer, Modigliani and Miller Theory and Agency Theory, and use both primary and secondary data collected from National Transport and Safety Authority, Kenya and Registrar of Motor vehicles, Kenya target populations, namely number of countries in Europe and North America and the number of insurance companies in Kenya. This study is of significance to the business communities, scholars and researchers, the government and the general public by: (1), providing a better understanding for designing and formulating risk management policy in their organizations, (2), providing mechanism for investing the foregone insurance premium and (3), strengthening knowledge and further research in this area. In summary this study is tenable and a better alternative to ever increasing insurance premiums.
\end{abstract}

Keywords: alternative method, earnings, insurance, internal rate of return, mitigating, risk

\section{Introduction}

Business organizations are facing hard economic times due to high operating costs and complex risks. Complexity of risk is making corporations to incur heavy costs to mitigate. Corporate governance requires that the management develops frameworks, structures and guidance to manage enterprise risk. ISO 31000 defines risk management as the effect of uncertainty on objectives (whether positive or negative) followed by coordinated and economical application of resources to minimize, monitor, and control the probability and/or impact of unfortunate events or to maximize the realization of opportunities. Cadbury Report (1992) on the other hand defines corporate governance as 'the system by which companies are directed and controlled'.

There is therefore a need to find ways in which corporations would cut down on operating costs without compromising their safety as regards to risk. Maguire (2008) defines operating cost as an ongoing cost for running a product, business, or system. While, risk is defined in ISO 31000 as "the effect of uncertainty on objectives". This paper borrows heavily from corporate governance principles in finding alternative means of managing risk at the lowest possible cost, while increasing firm's earnings. It also borrows from the work of Myron, Menton and Fischer which, according to Buehler, Freeman, and Hulmer (2008) working paper on the Risk Revolution, the search for a better way of managing risk stated in 1940s when academics started to advance on their understanding of risk trade-off in investment management in their publication on option pricing. This was during the foundation of modern risk management. According to Buehler et al. (2008), most corporations manage risk by contracting insurance. This according to them was a strategy mainly to manage downside risk. 
Research conducted by the ERM Initiative (2014), on the Current State of Enterprise Risk Management found that organizations continue to face an increasing volume and complexity of risks.

European Union Agency for Network and Information Security (ENISA) (2016), defines Risk Management Strategy as an integrated business process that incorporate all of the risk management processes, activities, methodologies and policies adopted and carried out in an organization.

Having examined the definitions of risk and its management in this study, the alternative model developed by this study is foregoing insurance contracts, and, investing foregone insurance premium on viable income generating investments whose rates of returns equal or exceed internal rate of return (IRR) of the corporation. Lajos (2011) in his study on Net Present Value verses Internal Rate of Return, summarized that the investment-profitability decisions need the knowledge of the IRR value in reflecting profitability on capital. According to him, the information guarantee the making of relevant decisions. Insurance on the other hand, according to Madura, (2010), is the payment to the insured or named beneficiary under conditions specified by the insurance policy contract. According to him, the conditions under insurance contract result in expenses or lost income, so the insurance is a mean of financing protection.

The premium charged for insurance contract for each insurance policy is based on probability of the condition on adverse condition will happen and the pooling concept. According to Insurance Regulatory Authority, Kenya, (2016), the concept in motor insurance is that a purchase of motor insurance contributes a sum of money called premium into a common pool and the few unfortunate contributors who suffer losses are paid out of this pool. The insurance premium paid by an organization is a charge on its profits. Analysis of data on rates of comprehensive insurance premiums collected from all the 34 insurance companies in Kenya give various rates of premium ranging from 4 percent to 8 percent as shown in Table 8 . The computed mean rate of insurance premium based on the data in Table 8 is 7.1 percent.

\subsection{Statement of Research Problem}

Business organizations are facing hard economic times due to high operating costs resulting from high cost of inputs. One of the input cost relates to cost of mitigating risks, also known as insurance costs. Traditional techniques of insurance contracts used by organizations to protect their businesses against ever increasing risk exposures are expensive and unsustainable. It is on this background that this study sought to find an alternative method of mitigating risks, with near to zero cost but on the other hand provide benefits to the corporation in terms of additional earnings and develop a model for computing such benefits.

\subsection{The Purpose and Objective of the Study}

The purpose and objective of this study was to find an alternative method of mitigating risk in medium and large corporations which are cheaper than the current traditional methods. Specifically, this study sought:

(1) To develop an alternative method of mitigating risk in medium and large corporations

(2) To develop a Model for computing benefits accruing to the firm as result of using the new alternative method of mitigating risk.

\subsection{Significance of the Study}

The developed model in this study will be of significance to the various groups of persons and institutions. First, is to the business community and the government by enabling them understand how to protect their business without incurring heavy costs. Second, to provide the business community with the basis of designing risk mitigating policies. Third, is to complement existing studies in this area, contribute knowledge on alternative risk mitigating methods. Forth, providing business corporations with the basis of optimizing their profits and finally strengthen the foundation for further research in this area by researchers.

\subsection{Limitations of the Study}

This study encountered the following limitation; Methodological difficulty. Since this involved the use of secondary data, obtaining data from National Transport and Safety Authority (NTSA) and the Traffic Police was a challenge. To solve this problem, this study used data collected by other institutions and government agencies through internet, which were relevant to this study.

\subsection{Assumptions of the Study}

This study was based on the following assumptions: (1), the secondary data used in this study present background and situations, which enable the findings of this study to be applied in other countries, and (2), the alternative method and the developed model will apply to other risks that require hedging and mitigation. 


\subsection{Scope of the Study}

Risk mitigating model developed by this study is restricted to medium and large organizations, and non-statutory insurance contracts.

\subsection{The Alternatives Risk Mitigating Methods}

The principle behind the Alternatives Risk Mitigating Methods proposed in this study is foregoing insurance contracts and investing the foregone insurance premiums in: (1) financial assets, (2), plough back, (3) sinking fund and / or any other investment whose rate of return is higher than the firm's IRR. These investments are expected to generate earnings to the corporation, measured at the firm's internal rate of return (IRR). As such, the model developed by this paper is;

$$
\pi=\sum_{1}^{n}(1+r)^{t} p+q(c-y)+s
$$

Where:

$\pi$ is the earnings accrued as a result of this method

$r$ is the organizations internal rate of return (IRR)

$\mathrm{p}$ is the asset's market insurance premium foregone

$\mathrm{q}$ is zero, if no adverse condition during the year, and, -1 if an adverse condition

occurs during the year.

$\mathrm{c}$ is the cost of asset involved in adverse condition

$\mathrm{y}$ is the accumulated depreciation at the time of adverse condition.

$\mathrm{s}$ is the amount received on disposal of salvage

$t$ is the time horizon of the investment

\section{Literature Review and Past Studies}

\subsection{Literature Review}

This study applied Actuarial Theory, Financial Theory of Risk Transfer, Modigliani and Miller Theory and Agency Theory.

\subsubsection{Actuarial Theory}

The first theory applied in this study is the Actuarial Theory, developed by Bruno de Finetti in late 1950s. According to this theory, firm value is the present value of the future dividends to shareholders. According to agency theory and stakeholders theory, the ultimate goal of a firm is the maximization of shareholders wealth and the stakeholders interests. Shareholders wealth leads to increased value of the firm. This theory therefore, is important to this study because; (1) it looks at the stream of dividend to shareholders, which will increase with application of this new Alternative Mitigating Method. (2), its findings are based on the actuarial theory of probability, which states that, avoiding insolvency maintains the firm's earning ability and so increases its value by paying a cost to mitigate, offset, or transfer divisible risk in order to avoid distress may therefore make sense.

\subsubsection{Financial Theory of Risk Transfer}

The second theory applied in this study is the Financial Theory of Risk Transfer, formulated by Garry \& Underwood, (2012). According to this theory, the reasons why it is worthwhile for a firm to reduce, or transfer specific risk, even at a cost, are cost of financial distress, regulations and taxation and relationship with shareholders. This theory is relevant in this study since the main objective of this study is to cut down on operating costs thus reducing financial distress.

\subsubsection{Modigliani and Miller Theory}

The third theory applied in this study is the Modigliani and Miller Theory founded by Franco Modigliani and Miller H. M. in 1958. It states that for a firm owned by diversified investors, any risk that can be diversified against broader holding is irrelevant to owners - and thus not worthwhile for the firm to incur mitigation cost for such risk. This is the spirit of this study. In view of the foregoing, this study suggests that a firm should not incur a cost to insure a risk that can be diversified or mitigated at no cost.

\subsubsection{Agency Theory}

Finally, this study also applied Agency Theory. Agency Theory relates to conflict between the principal (shareholders) and the agent (management). The pure finance view of the firm is that managers must maximize 
the shareholders' wealth. According to this theory, reducing risk through hedging or other strategies can signal to bond holders, potential creditors and future investors that the firm will not take excessive risk with their money. When mitigating, Garry and Underwood (2012) states that insurance face special issues which include agency theory complications between policy holder and debtholder and / or other special vulnerability to effects of financial distress and reinsurance as dominant form of hedging. Accordingly, Pandey, (2011), states that under the agency theory of corporate governance, the main concern is to develop rules and incentives, based on implicit or explicit contracts, to eliminate or at least, minimize the conflict of interests between owners and managers. In agency theory, one way of mitigating agency problems is to give ownership right through stock option to managers as such, agency problems varnish when managers become part of owners, thus becoming an alternative to insurance.

\subsection{Past Studies}

This study applied past studies by: Staking (1995) and Olawale (2014), Smith and Stulz (1985), Muhammad, (2012) and Buchmueller, Glenn, Denzil, and Elizabeth (2009).

Studies by Staking and Babbel, (1995) found that using risk management to avoid financial distress increased the insurer's market value. In addition, the study states that insurers employ sophisticated asset-liability management techniques to manage their exposure to interest rate risk.

Olawale (2014), and Muhammad, (2012), in their studies on the Effect of Credit Risk on the Performance of Commercial Banks in Nigeria found that there was a significant relationship between bank performance and credit risk management.

On the other hand, Smith and Stulz (1985) in their study, identified cost of financial distress that "leak out of" financial markets and ended up as profits and salaries of some law firms and liquidation bureaus, but out of realm of publicly traded firms.

Study by Buchmueller, Glenn, Denzil, and Elizabeth (2009), on Advantageous Selection in Private Health Insurance in Australia findings suggested that there was other factors that positively affect the demand for private health insurance but are negatively related to expected claims. According to him, two possible factors were risk aversion and income.

\section{Research Methods}

\subsection{Research Design}

This study employed both Descriptive Survey Research Design and Inferential Statistics. According to Fox \& Bayat (2007), Descriptive Research is aimed at casting light on current issues or problems through a process of data collection that enables them to describe the situation more completely than was possible without employing this method. Similarly, Oso and Onen (2009) defines research design as a systematic collection of data in a standardized form from an identifiable population or representative to collect data. Inferential Statistical Analysis on the other hand, according to SAS Institute Inc. (2003), involves using information from a sample to make inferences, or estimates, about the population. This study employed Descriptive Survey Research Design in which a census and a samples size was drawn; (1), census of target population of 34 motor vehicle insurance companies in Kenya, and (2), a sample size of 5.8 percent of target population of the number of countries in Europe and North America. Descriptive Research Design in this study was useful in analysis of data that helped describe, show or summarize data in a meaningful way. Similarly, the methods of Inferential Statistics was useful in the estimating parameters, testing of statistical hypotheses and drawing conclusions.

\subsection{Target Population}

Target populations in this study were: (1), 34 Motor Vehicle Insurance Companies registered with Insurance Regulatory Authority, Kenya. And (2), 70 countries in Europe and North America, according to according to worldatlas.com (2016). This study selected these two unit of analysis because of their data infrastructure. According to Economic \& Social Research Centre, (2015), the UK has a world-leading data infrastructure for Social and Economic Research that provides a huge opportunity to address some of the most pressing challenges facing society today and into the future. Similarly, according to Katherine, (1998), secondary data can be useful to researchers because they are easily obtainable and comprehensive source of information that usually covers long periods of time. Target Population is defined by Statistics Canada Quality Guidelines, (2009), as the set of units about which information is wanted and estimates are required.

\subsection{Sample Size}

This study used a simple formula of 20 percent of the Target Population in determining the Sample Sizes from a 
Target Population of 47 countries in Europe and, a convenience sampling for selecting two countries from a Target Population of 23 countries in North America as shown in Table 1. In addition, this study employed census in collecting data on Motor Vehicle Insurance Premium Rates from 34 insurance companies dealing in motor vehicle insurance in Kenya.

Table 1. Sample size

\begin{tabular}{llll}
\hline Countries & & & \\
\hline Continent & Target Population & Sample percentage & Sample Size \\
\hline Europe & 47 & 20 & 9 \\
N. America & 23 & Convenience & 2 \\
Total & 70 & & 11 \\
\hline
\end{tabular}

\subsection{Sampling Procedures}

This study used simple sampling technique to select sampled countries in Europe and convenience sampling to select countries in North America. This was followed by use of secondary data obtained by way of internet from the sampled countries. For reliability and removal of biases, this study used simple random technique to select 9 countries from Target Population of 47 countries in Europe and Convenience sampling to selected 2 countries from a target population of 23 countries in North America. Data of the number of vehicles in use in each of the 11 countries was obtained from web site by way of internet.

\subsection{Types of Data}

This study used both primary and secondary data. Primary data was used in analyzing Insurance Premium Rates from motor vehicle insurance companies in Kenya while secondary data was used to analyze the number of Vehicles in Use and the number of Road Traffic Accidents in Europe and North America. The use of secondary data was necessary since it was unfeasible for this study to collect on its own. According to Economic \& Social Research Centre - Business and Local Government Data Research Centre (2015), secondary data analysis initiative aims to deliver high-quality high-impact research through the deeper exploitation of major data resources created by other agencies. These statistics can be useful to researchers because they are easily obtainable and comprehensive source of information that usually covers long periods of time.

\subsection{Data Collection Instruments}

Primary data on Rates of motor vehicle insurance premiums in Kenya was collected by administering questionnaires to 10 licensed insurance brokers in Kenya. While, schedules were used to collect secondary from sampled countries in Europe and North America on the number of vehicles in use and the number of road traffic accidents from the year 2009 to 2013.

\subsubsection{Instrument Validity and Reliability}

Reliability Test carried in this study was expressed as a coefficient of zero to one; where zero indicated no reliability and one indicated perfect reliability using Karl Pearson's Product Moment Correlation. Data collection problems were minimized through pilot testing and validity and quality checks. Hence Reliability Test on the data collected gave a correlation coefficient of 0.995 , indicating a strong reliability.

\subsection{Statistical Analysis}

This study analyzed data collected using tables and computations of means and standard deviations.

\subsubsection{Number of Registered Vehicles in Use}

Statistical data on the number of registered vehicles in use in Europe and North America for the period 2009 to 2013 is tabulated in Table 2. The results of Table show that the average number of registered vehicles in use over the period 2009 to 2013 was 40551154 with a standard deviation of 68770 . 
Table 2. Number of vehicle in use in Europe and North America in "000"

\begin{tabular}{llllllllllll}
\hline Year & UK & Sweden & Germany & Belgium & Denmark & Georgia & Finland & Spain & Italy & Canada & USA \\
\hline 2013 & 36468 & 5074 & 47015 & 6241 & 2780 & 790 & 3642 & 27155 & 41830 & 22334 & 252715 \\
2012 & 35764 & 5018 & 46538 & 6184 & 2705 & 750 & 3555 & 27481 & 42000 & 21705 & 251497 \\
2011 & 35632 & 4963 & 45984 & 6138 & 2682 & 710 & 3457 & 27596 & 42067 & 21616 & 248932 \\
2010 & 35479 & 4875 & 45262 & 6040 & 2664 & 687 & 3331 & 27513 & 41650 & 21231 & 248232 \\
2009 & 35217 & 4829 & 44631 & 5903 & 2644 & 647 & 32100 & 27389 & 41213 & 20792 & 248972 \\
Total & 178560 & 24759 & 229430 & 30506 & 13475 & 3584 & 46085 & 137134 & 208760 & 107678 & 1250348 \\
Average & 35,712 & 4,952 & 45,886 & 6,101 & 2,695 & 717 & 9,217 & 27,427 & 41,752 & 21,536 & 250,070 \\
\hline
\end{tabular}

Source: Organization internationale des constructeurs d' automobile, Paris, France.

\subsubsection{Number of Road Traffic Accidents}

Table 3 in this study gives statistical data of Road Traffic Accidents in Europe and North America for the period 2009 to 2013. The results of the Table show that the average number of road traffic accidents during the period was 229140 with standard deviation of 443244.

Table 3. Road traffic accidents in Europe and North America

\begin{tabular}{llllllllllll}
\hline Year & UK & Sweden & Germany & Belgium & Denmark & Georgia & Finland & Spain & Italy & Canada & USA \\
\hline 2013 & 144480 & 14942 & 291105 & 35632 & 2984 & 5510 & 5334 & 89519 & 181227 & 116923 & 1621073 \\
2012 & 151346 & 16636 & 299637 & 38057 & 3124 & 5359 & 5725 & 83115 & 188228 & 118439 & 1665186 \\
2011 & 157068 & 16274 & 306266 & 42119 & 3525 & 4486 & 6408 & 83027 & 205638 & 121159 & 1559832 \\
2010 & 160080 & 16627 & 288297 & 40569 & 3498 & 5099 & 6072 & 85503 & 212997 & 125203 & 1572400 \\
2009 & 169805 & 17858 & 310806 & 47798 & 4959 & 5482 & 6414 & 88251 & 205405 & 123192 & 1517000 \\
Total & 1082779 & 82337 & 1496111 & 204175 & 18090 & 25936 & 29953 & 429415 & 993495 & 604916 & 7935491 \\
Average & 216555.8 & 16467.4 & 299222.2 & 40835 & 3618 & 5187.2 & 5990.6 & 85883 & 198699 & 120983.2 & 1587098
\end{tabular}

Source: UNECE 2015. Statistics of Road Traffic Accidents in Europe and North America.

\subsection{Inferential Statistics}

\subsubsection{The Analysis of Variance (ANOVA)}

This study used sampling distribution of $F$ ratio to measure how different the means are relative to the variability within each sample by testing the hypothesis of the data using a parametric technique developed by Fisher (1947); the Analysis of Variance (ANOVA) at 5\% significant level. The results of the hypotheses testing obtained in this study were then compared to $F$ Tables $\left(\mathrm{F}_{\mathrm{T}}\right)$ developed by Fisher (1957) to draw conclusion using ANOVA model in Table 4.

Table 4. Analysis of variance model

\begin{tabular}{llll}
\hline Source of variation & Sum of squares & Degree of freedom & Mean square \\
\hline Between & $\mathrm{S}_{\mathrm{A}}=\sum^{\mathrm{n}} \sum^{\mathrm{k}}(\overline{\mathrm{X}} \mathrm{i}-\overline{\mathrm{X}})^{2}$ & $\mathrm{n}-1$ & $\mathrm{~S}_{\mathrm{A}}=\mathrm{S}_{\mathrm{A}} /(\mathrm{n}-1)$ \\
Within & $\mathrm{S}_{\mathrm{E}}=\sum^{\mathrm{n}} \sum^{\mathrm{ki}}\left(\mathrm{x}_{\mathrm{i}}-\overline{\mathrm{X}}\right)^{2}$ & $\mathrm{k}-\mathrm{n}$ & $\mathrm{S}_{\mathrm{E}=} \mathrm{S}_{\mathrm{E}} /(\mathrm{k}-\mathrm{n})$ \\
Total & $\mathrm{S}_{\mathrm{T}}=\sum^{\mathrm{n}} \sum^{\mathrm{k}}\left(\mathrm{x}_{\mathrm{ij}}-\mathrm{x}\right)^{2}$ & $\mathrm{n}-1$ & $\mathrm{~S}_{\mathrm{T}=} \mathrm{S}_{\mathrm{T}} /(\mathrm{k}-1)$ \\
\hline
\end{tabular}

This study formulated the hypotheses as follows:

(1) The means of the number of registered vehicles in use

$\mathrm{H}_{0}$ : The means of the number of registered vehicles in use are the same for all samples. 
$\mathrm{H}_{1}$ : The means of the number of registered vehicles in use are not the same for all samples.

Table 5. Analysis of variance of the number of vehicle in use

\begin{tabular}{llll}
\hline Source of variation & Sum of squares & Degree of freedom & Mean square \\
\hline Between & $249,918,833,672.91$ & 10 & $24,991,883,367.29$ \\
Within & $39,022,758.80$ & 44 & $886,880.88$ \\
Total & $249,957,856,431.71$ & 54 & $\mathrm{~S}_{\mathrm{T}}{ }^{\prime}$ \\
& $\mathrm{Fc}=28179.53$ & & $\mathrm{~F}_{\mathrm{T}}=2.05$ \\
\hline
\end{tabular}

Since $F_{C}=28179.53$ was greater than $F_{T, 95 \%}$, this study rejects the hypothesis, and concludes that the eleven samples did not come from the same population and that the sample means are significantly different.

(2) The means of Road Traffic Accidents

$\mathrm{H}_{0}$ : The means of the number of Road Traffic Accidents are the same for all samples.

$\mathrm{H}_{1}$ : The means of the number of Road Traffic Accidents are not the same for all samples.

Table 6. Analysis of variance table-road traffic accidents

\begin{tabular}{llll}
\hline Source of variation & Sum of squares & Degree of freedom & Mean square \\
\hline Between & $10,594,383,306,789.50$ & 10 & $1,059,438,330,679$ \\
Within & $14,741,966,496.40$ & 44 & $335,044,693$ \\
Total & $10,609,125,273,285.90$ & 54 & $\mathrm{~S}_{\mathrm{T}}$ \\
& $\mathrm{Fc}=3,162.08$ & & $\mathrm{~F}_{\mathrm{T}}=2.05$ \\
\hline
\end{tabular}

Similarly, since $\mathrm{F}_{\mathrm{C}}=3162.08$ was greater than $\mathrm{F}_{\mathrm{T}, 95 \%}=2.05$ this study rejects the hypothesis, and concludes that the eleven samples did not come from the same population and that the sample means are significantly different.

\subsubsection{Probability of Adverse Condition}

This study computed probability of adverse condition by calculating the percentage of road traffic accidents over the number of vehicle in used using the results of Table 2 and Table 3. The finding shows that the average percentage of road traffic accidents over the number of vehicles in use in Europe and North America was 0.565 percent.

This study developed a model for calculation adverse condition based on probability as follows:

$$
P(A)=\alpha / \varnothing \times 100
$$

Where:

$\mathrm{P}(\mathrm{A})$ is the probability of adverse condition

$\alpha$ is the number of road traffic accidents in a year

$\varnothing$ is the number motor vehicles in use in a year

Based on the data in Tables 2 and 3, using equation 2, $\mathrm{P}(\mathrm{A})$ is

$\alpha=229140$

$\varnothing=40551154$

Therefore, $\mathrm{P}(\mathrm{A})=229140 / 40551154 * 100=0.565$ percent.

In addition to model 1 and model 2, this study developed a third model of calculating the number of vehicles required by a firm to make one adverse condition, based on $\mathrm{P}(\mathrm{A})$ obtained earlier in this study. The model is as follows:

$$
N=1 / P(A)
$$

Where $\mathrm{N}$ is the number of vehicle be owned by a firm. 
In this study, $\mathrm{P}(\mathrm{A})$ is 0.565 percent. Therefore the number of vehicles a firm require for an adverse condition of one vehicle is $1 / 0.565=177$ vehicles.

\subsubsection{Insurance Premiums Charged by Insurance Firms}

Data collected on Insurance premium rates by this study show that in Kenya there are 34 registered insurance companies dealing with motor vehicle insurance according Insurance Regulatory Authority (2016), as given in Table 7. Since the number of insurance firms is small, this study used census to collect data on insurance premium rates as given in Table 8 . The result of the table give mean rate of 7.1 percent.

Table 7. Target population: motor vehicle insurance companies in Kenya

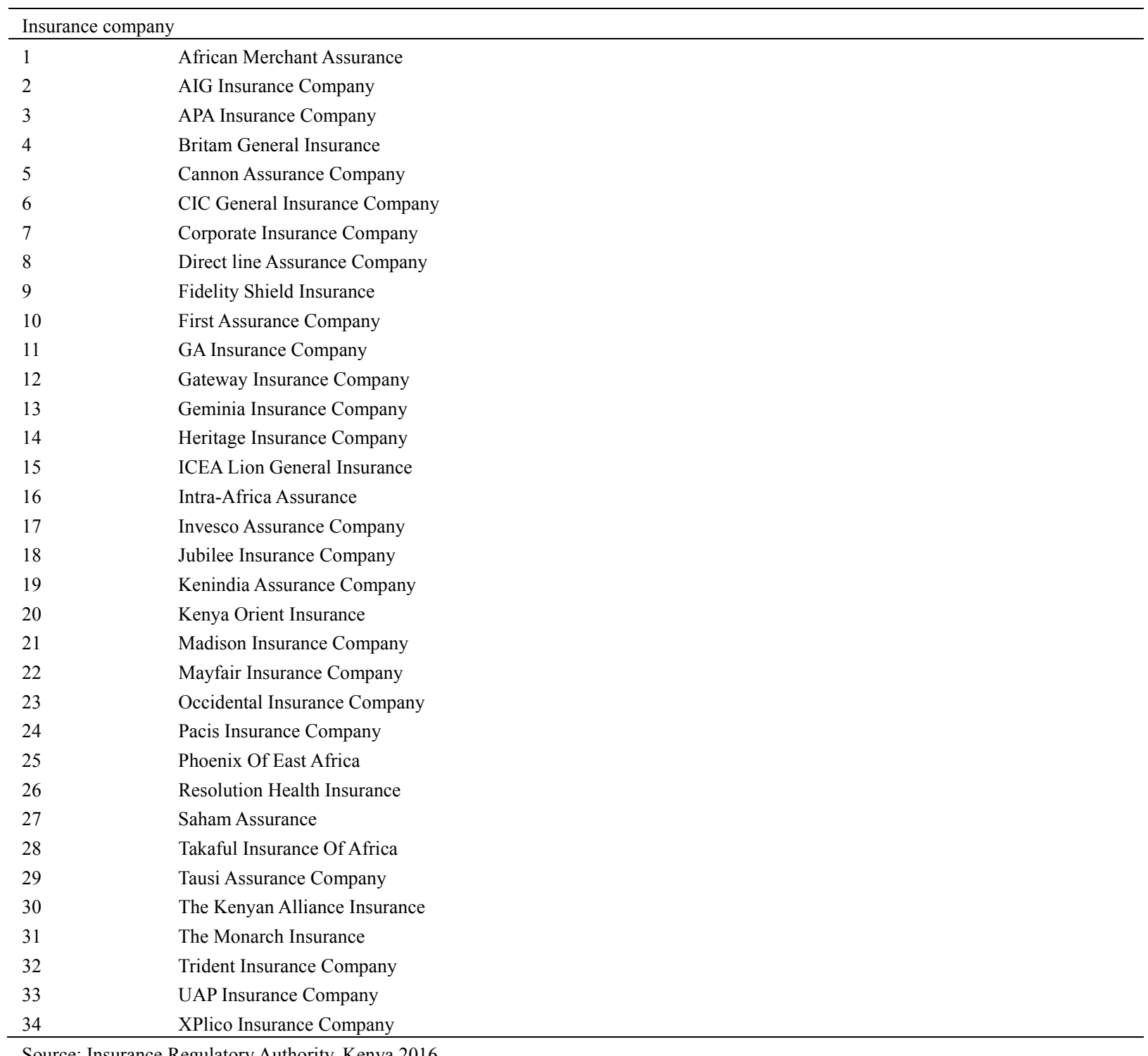


Table 8. Insurance premium rates in Kenya

\begin{tabular}{lll}
\hline Rate $\%(\mathrm{x})$ & Number of firms $(\mathrm{f})$ & $\mathrm{fx}$ \\
\hline 8.0 & 8 & 64.0 \\
7.5 & 9 & 67.5 \\
7.0 & 8 & 56.0 \\
6.5 & 5 & 32.5 \\
6.0 & 2 & 12.0 \\
5.5 & 1 & 5.5 \\
4.0 & 1 & 4.0 \\
- & $\sum \mathrm{f} 34$ & $\sum \mathrm{fx} 241.5$ \\
\hline
\end{tabular}

\subsection{Illustration}

Based on $1^{\text {st }}$ and $2^{\text {nd }}$ assumptions in this study, this study illustrates the practability of the Model developed in this study using the mean obtained in Table 8 and the results of Tables 2 and 3 as follows:

Given a firm with:

10 vehicles at a cost of Ksh. 10000000 ,

IRR of $5 \%$,

Time; 3years,

Depreciation rate $25 \%$ per year, (straight line);

Premium rate of $7.1 \%$, (computed in Table 8 );

Salvage value of Ksh. 100000 and,

Assumption: adverse condition occurs in the third year;

Earnings of the firm for the period using this model are:

$$
\pi=\sum_{1}^{n}(1+r)^{t} p+q(c-y)+s
$$

Year $1 \pi=(1.05)^{3} * 7100000+0+0=8219137.5$

Year $2(1.05)^{2} * 7100000+0+0=7827750$

Year $3(1.05) * 7100000+-1(10,000,000-7,500,000)+100,000=5055000$

\section{$\pi=\underline{\underline{\mathbf{2 1 1 0 1 8 8 7 . 5}}}$}

In the event of no adverse condition in the three years period, earnings are:

\section{$\pi=\underline{\mathbf{2 3 5 0 1 7 7 8 . 5}}$}

For these illustrations, these are the amount of earnings lost by a firm using the traditional method of insurance contract.

\section{Conclusion}

This study has illustrated the viability of employing the new Alternative Method of Mitigating Risk in firms. It has demonstrated that by employing the Alternative Method of Mitigating Risk in firms, the firm not only reduces the operating costs, but also generates additional earnings resulting from invested foregone insurance premiums. This study has shown that the eleven samples did not come from the same population and concludes that the sample means are significantly different. Based on the secondary data, the model and illustration, this study finds that the probability of an adverse condition in a year in regard to motor vehicles is less than one percent and thus concludes that: (1), where the probability of an adverse condition is small, the alternative method of mitigating risk is tenable and provides more economic benefits to corporation if employed. And, (2), the developed Model of calculating additional earnings in this study provides a better understanding on how a corporation can benefit from employing the alternative method. 


\section{Recommendations}

This study recommends further research in this area so as to complement existing studies and contribute to knowledge.

\section{References}

Automotive Market $\quad$ Research. $\quad$ (2016). $\quad$ Retrieved from https://hedgescompany.com/automotive...statistics/auto-mailing-lists-and-marketing

Buehler, K., Freeman, A., \& Hulme, R. (2009). Risk Revolution. Working Paper on Risk. Minky and Coimpany. Retrieved from http://www.mckinsey.com/.../risk/.../1_the_risk_revoluti

Cadbury Report. (1992). The Financial Aspects of Corporate Governance. London. Gee. Retrieved from http://www.ecgi.org/codes/documents/cadbury.pdf

De Finetti, B. (1957). Su un' impostazione alternativa della teoria colletiva del rischio. Transactions of the XVth International Congress of Actuaries, 2, 433-443.

Economic \& Social Research Centre Business and Local Government Data Research Centre. (2015). Retrieved from http://www.blgdataresearch.org/call-for-secondary-data-analysis-initiative-phase-3-now-closed/

Edward, R. F. (2001). Stakeholders Theory of Modern Corporation Perspectives in Business Ethics Sie.

ENISA. (2016) Corporate Risk Management Strategy. Retrieved from http://www.enisa.europa.eu/activities/riskmanage-inventory/rm-process/crm-strategy

ERM Initiative's. (2014). Report on the Current State of Enterprise Risk Management: Opportunities to Strengthen Integration with Strategy. Retrieved from http:// http://www.erm.ncsu.edu

Fisher, R. A. (1947). The design of Experiments (4th ed.). Oliver and Boyd: Edinburgh.

Fisher, R. A., \& Yates, F. (1957). Statistical Tables for Biological, Agricultural and Medical Research. New York: Hafner Publishing Company.

Fox, W., \& Bayat, M. S. (2007). A Guide to Managing Research. Juta Publications.

Garry, V., \& Underwood, A. (2012). Value of Risk Reduction. Casualty Actuary Society, 2.

Gottlieb, D. (2012). Prospect Theory, Life Insurance, and Annuities Insurance Regulatory Authority Retrieved from http://www.ira.go.ke/index.php/component/content/article?layout=edit\&id=256

ISO 31000. (2009). Risk management - A practical guide for SMEs. Published in Switzerland.

Katherine, M. M. (1998). Partnership \& Household Livelihood Security Unit.

Kevin, B., Andrew, F., \& Ron, H. (2008). The Risk Revolution. Working paper. London: McKinsey and Company.

Lajos, J (2011). Net Present Value versus Internal Rate of Return. Economics \& Sociology, 4(1), 46-53.

Madura, J. (2010). Financial Institutions and Markets. South-Western Cengage Learning. USA.

Maguire, D. (2008). The business benefits of GIS: An ROI approach (1st ed.). Redlands Calif.: ESRI Press.

Modigliani, F., \& Miller, M. H. (1958). The Cost of Capital, Corporation Finance and the Theory of Investment. American Economic Review, 48, 261-297

Muhammad, N. (2012). Interdisciplinary Journal of Contemporary Research In business.

NTSA. (2016). Retrieved from http://www.ntsa.go.ke/.../FINAL\%202015\%20ROAD\%20SAFETY\%20STATU

Olawale, S. L. (2014). Social Science Research Network. Retrieved from http://papers.ssrn.com/sol3/papers.cfm?abstract_id=2536531

Oso, Y., \& Onen. (2009). A general guide to writing research and report: Kampala. A hand book.

Pandey, I. M. (2011). Financial Management (10th ed.). New Delhi. Vikas Publishing House PVT Limited.

SAS Institute Inc. (2003). JMP Statistics and Graphics Guide. Cary, NC: SAS Institute Inc.

Smith, C. W., \& Stulz R. M. (1985). The Determinants of Firms' Hedging Policies. Journal of Financial and Quantitative Analysis, 20(4), 391-405.

Staking, K. M., \& Babbel, D. F. (1995). The Relationship between Capital Structures, Interest Rate Sensitivity, and Market Value in the Property-Liability Insurance Industry. The Journal of Risk and Insurance, 62(4), 
670-718.

Statistics Canada Quality Guidelines. (2009). Retrieved from https://www.google.com/\#q=Statistics + Canada + Quality + Guidelines\%2C+(2009)\%2C +

Statistics Canada, (2009). Quality Guideline (5th ed.). Retrieved from http://unstats.un.org/unsd/dnss/docs-nqaf/Canada-12-539-x2009001-eng.pd

UNECE. (2015). Statistics of Road Traffic Accidents in Europe and North America. Retrieved from http://www.unece.org/trans/resources/publications/transport-statistics/2015/statistics-of-road-traffic-acciden ts

World Atlas. (2016). Retrieved from http://www.worldatlas.com/cntycont.htm

\section{Copyrights}

Copyright for this article is retained by the author(s), with first publication rights granted to the journal.

This is an open-access article distributed under the terms and conditions of the Creative Commons Attribution license (http://creativecommons.org/licenses/by/4.0/). 